\title{
Clinical characteristics and prognostic factors of COVID-19 patients progression to severe: a retrospective, observational study
}

\author{
Yunfei Liao ${ }^{1,}{ }^{*}$, Yong Feng ${ }^{2,}{ }^{,}$, Bo Wang ${ }^{3,}{ }^{*}$, Hanyu Wang ${ }^{1}$, Jinsha Huang ${ }^{4}$, Yaxin $\mathrm{Wu}^{5}$, Ziling $\mathrm{Wu}^{1}$, \\ Xiao Chen ${ }^{1}$, Chao Yang ${ }^{6}$, Xinqiao Fu , Hui Sun ${ }^{1}$ \\ ${ }^{1}$ Department of Endocrinology, Union Hospital, Tongji Medical College, Huazhong University of Science and \\ Technology, Wuhan 430022, China \\ 2Department of Orthopedics, Union Hospital, Tongji Medical College, Huazhong University of Science and \\ Technology, Wuhan 430022, China \\ ${ }^{3}$ Department of Rehabilitation, Wuhan No.1 Hospital, Tongji Medical College, Huazhong University of Science and \\ Technology, Wuhan 430022, China \\ ${ }^{4}$ Department of Neurology, Union Hospital, Tongji Medical College, Huazhong University of Science and \\ Technology, Wuhan 430022, China \\ ${ }^{5}$ First Clinical College, Tongji Medical College, Huazhong University of Science and Technology, Wuhan 430030, \\ China \\ ${ }^{6}$ Department of Vascular Surgery, Union Hospital, Tongji Medical College, Huazhong University of Science and \\ Technology, Wuhan 430022, China \\ ${ }^{7}$ Outpatient Department, Union Hospital, Tongji Medical College, Huazhong University of Science and Technology, \\ Wuhan 430022, China \\ *Equal contribution
}

Correspondence to: Hui Sun; email: sunny68@hust.edu.cn

Keywords: COVID-19, clinical characteristics, prognostic factors, nomogram

Received: May 9, 2020

Accepted: July 30, 2020

Published: October 14, 2020

Copyright: (C) 2020 Dou et al. This is an open access article distributed under the terms of the Creative Commons Attribution License (CC BY 3.0), which permits unrestricted use, distribution, and reproduction in any medium, provided the original author and source are credited.

\section{ABSTRACT}

The outbreak of coronavirus disease 2019 (COVID-19) has become a world-wide emergency. The severity of COVID-19 is highly correlated with its mortality rate. We aimed to disclose the clinical characteristics and prognostic factors of COVID-19 patients who developed severe COVID-19. The study enrolled cases (no=1848) with mild or moderate type of COVID-19 in Fangcang shelter hospital of Jianghan. A total of 56 patients progressed from mild or moderate to severe. We used least absolute shrinkage and selection operator regression model to select prognostic factors for this model. The case-severity rate was $3.6 \%$ in the shelter hospital. They were all symptomatic at admission. Fever, cough, and fatigue were the most common symptoms. Hypertension, diabetes and coronary heart diseases were common co-morbidities. Predictors contained in the prediction nomogram included fever, distribution of peak temperature $\left(>38^{\circ} \mathrm{C}\right)$, myalgia or arthralgia and distribution of Creactive protein ( $\geq 10 \mathrm{mg}$ per $\mathrm{L}$ ). The distribution of peak temperature $\left(>38^{\circ} \mathrm{C}\right)$ on set, myalgia or arthralgia and Creactive protein ( $\geq 10 \mathrm{mg}$ per $\mathrm{L}$ ) were the prognostic factors to identify the progression of COVID-19 patients with mild or moderate type. Early attention to these risk factors will help alleviate the progress of the COVID-19.

\section{INTRODUCTION}

Recent study has shown that the coronavirus disease 2019 (COVID-19) has the ability of human-to-human transmission and becomes a world-wide emergency [1]. The World Health Organization (WHO) has recently declared COVID-19 outbreak in several countries. Since January 2020, thousands of new patients have 
been diagnosed every day, which requires enormous medical resources. The surge of infections placed huge pressure on the national medical system [2].

The Fangcang shelter hospitals in Wuhan were largescale, temporary hospitals, rapidly built by converting existing public venues, such as exhibition centers and stadiums, into health-care facilities. They were served to isolate patients with mild or moderate COVID-19 from their families and communities, while providing basic medical care, disease monitoring, food, shelter, and social activities [3]. Patients with mild or moderate COVID-19 who met additional admission criteria were isolated and treated in the Fangcang shelter hospitals, whereas patients with severe or critical COVID-19 received medical care in traditional hospitals [3-6]. Fangcang shelter hospitals provide basic medical care and monitored the progression of disease. As some patients remain experienced progression of COVID-19 or development of severe chronic diseases, they were transferred in a timely manner to the designated higherlevel hospitals. The clinical characteristics of patients transferred to the designated hospital were important for the revision of admission criteria of COVID patients in Fangcang shelter hospitals.

The severity of the COVID-19 determines the fatality rate and the medical resource usage. The case-severity (mild or moderate progressing to severe case) rate was an important benefit index for therapeutic efficacy assessment in shelter hospital. Dynamic observation the risk factors of mild to severe patients is contribute to great value for early prognosis and treatment. Therefore, a retrospective review of overall medical record was performed in Fangcang shelter hospital of Jianghan, which received the largest number of patients among Fangcang shelter hospitals in Wuhan. A total of 1848 cases with mild or moderate COVID-19 were included and 521 cases transferred to the designated hospital were analyzed. The clinical characteristics and prognostic factors of patients from mild or moderate to severe were detected as well.

\section{RESULTS}

\section{Outcomes and case-severity rate of patients in Fangcang shelter hospital}

Among 1848 enrolled patients, the age range was from 15 to 81 years, and $49.0 \%$ were men. From Feb 5th to Mar $9^{\text {th }} 2020,521(28.2 \%)$ patients were transferred to the designated hospitals for further treatment. Meanwhile, the other 1327 (71.8\%) patients reached the criteria of isolation release or discharge, (Figure 1). Among 521 patients transferring to the designated hospitals, $10.7 \%$ patients with severe type from mild or moderate type (56 cases), $6.9 \%$ (36 cases) patients with body temperature more than $38.5^{\circ} \mathrm{C}$ for 3 days or more after treatment, $15.0 \%$ (78 cases) patients with cancer or severe liver/kidney/heart disease, 45.9\% (239 cases) patients with the persistent positive nucleic acid testing after 2 weeks treatment, and $21.5 \%$ (112 cases) patients with other reasons (including new onset severe symptoms or mental illness or tremendous mental pressure or pregnant woman). The basic clinical characteristics of patients transferring to the designated hospitals were in Table 1.

The case-severity rate was identified as the proportion of mild or moderate type progressing to severe type in this study. A total of 56 patients have progressed from mild or moderate type to the severe type. The caseseverity rate of COVID-19 was $3.6 \%(67 / 1848)$ in the Fangcang shelter hospital of Jianghan.

\section{Clinical characteristics of patient progression from mild or moderate type to severe type}

In order to better display the clinical characteristics of mild or moderate to severe patients, 92 age-and sexmatched mild or moderate patients stayed in the Fangcang shelter hospital at the same time have been showed and compared as well. The severe patients have the following characteristics. Among 56 severe patients, 30 were male $(53.6 \%)$ and 26 were female (46.4\%). All the patients aged 28-73 years with an average age of 55 years (IQR 48.0-61.0). About 76.8\% of those patients was between 40 to 65 years. The median incubation time (onset to severe) was 10 days (IQR 8.0-16.0), 7/56 (12.5\%) less than 7 days, 34/56 $(60.7 \%)$ between $7-14$ days, 14/56 (25.0\%) more than 14 days. Meanwhile, the median time in mobile cabin was 4 days (IQR 3.0-8.0), 12/56 (21.8\%) less than 3 days, 29/56 (52.7\%) between 3-7 days, 14/56 (25.5\%) more than 7 days (Table 2).

The clinical manifestations at onset of those patients have been observed. There were no asymptomatic cases on admission. Besides, 43/56 (76.8\%) of patients were with fever on admission, $31 / 56(55.4 \%)$ of patients were once with fever over $38.0^{\circ} \mathrm{C}, 34 / 56(60.7 \%)$ with cough, $11 / 56(19.6 \%)$ with sore throat, $10 / 56(17.9 \%)$ with shortness of breath, $17 / 56$ (30.4\%) with myalgia or arthralgia, 11/56 (19.6\%) with diarrhea, 16 (28.6\%) with poor appetite, $32(57.1 \%)$ with fatigue.

There were $42.9 \%$ (24/56) of patients with comorbidity. The most common comorbidity was hypertension $(23.2 \%)$, followed by diabetes $(4 / 56,7.1 \%)$, coronary heart diseases $(4 / 56,7.1 \%)$, kidney diseases (1/56, $1.8 \%)$, cerebral infarction $(1 / 56,1.8 \%)$ and chronic obstructive pulmonary disease $(1 / 56,1.8 \%)$. 
At admission, lymphocytopenia was less common (in $35.7 \%$ of the patients), with a mean lymphocyte count of $1.70 \pm 0.72 \times 10^{9}$ per $\mathrm{L}$ in this study. Most of the patients showed elevated levels of C-reactive protein (CRP) at ill onset with a median CRP of $10.12 \mathrm{mg}$ per $\mathrm{L}$ (IQR 1.33-16.44). The CRP levels of 33.3\% patients were over $10 \mathrm{mg} / \mathrm{L}$. All the patients were examined by chest CT $6 \pm 3$ days after the onset of disease. As shown in the imaging, 24/56 (42.9\%) of patients were with bilateral distribution, followed by $22 / 56(39.3 \%)$ with local distribution, $11 / 56 \quad(19.6 \%)$ with multiple distribution, $7 / 56(12.5 \%)$ with unilateral distribution. Meanwhile, ground-glass opacity $(53 / 56,94.6 \%)$ was the most common morphological depiction, followed by $10 / 56(17.9 \%)$ patchy shadowing, $1 / 56 \quad(1.8 \%)$ interstitial abnormalities (Table 3).

According to the symptoms and signs, patients received different treatments. There were $16 / 42(38.1 \%)$ of patients with antibiotics, antivirus and traditional Chinese medicine, 5/42 (11.9\%) of patients with antivirus and antibiotics, 6/42 (14.3\%) of patients with antivirus and traditional Chinese medicine. There were 14 patients with no medicine records due to the short time of staying in Fangcang shelter hospital.

On March 12, those 56 patients were followed up by telephone and 4 lost. There were $5.8 \%(9 / 52)$ of the patients whose nucleic acid test results remain positive.
As shown in the CT scan, $96.2 \%(50 / 52)$ of the patients were recovery or improved, only $3.8 \%(2 / 52)$ of the patients got deterioration or new lesions. The clinical manifestations and laboratory findings were shown in Table 3.

\section{The prognostic factors of patients transforming from mild or moderate type to severe type}

There were 45 variables in the LASSO regression and the outcomes displayed that median incubation (onset to shelter) period ( $\geq 14$ days), fever, distribution of peak temperature $\left(>38^{\circ} \mathrm{C}\right)$, sputum production, sore throat, shortness of breath, myalgia or arthralgia, poor appetite, headache, diabetes and CRP $(\geq 10$ per L) were predictive factors for patients transforming from mild or moderate type to severe type with nonzero coefficients (Figure $2 \mathrm{~A}, 2 \mathrm{~B})$. Ten variables mentioned above were then included in the multiple logistic regression analysis. The results demonstrated that fever, distribution of peak temperature $\left(>38^{\circ} \mathrm{C}\right)$, myalgia or arthralgia and distribution of CRP ( $\geq 10$ per L) were significantly predictive factors (Table 4). Moreover, the model that incorporated the above independent predictors was developed and presented as the nomogram (Figure 2C). The calibration curves of this nomogram showed good agreement in this cohort (Figure 2D). The C-index of the prediction nomogram was 0.888 (95\% CI 0.839 0.937 ) for this cohort, which was confirmed to be 0.876

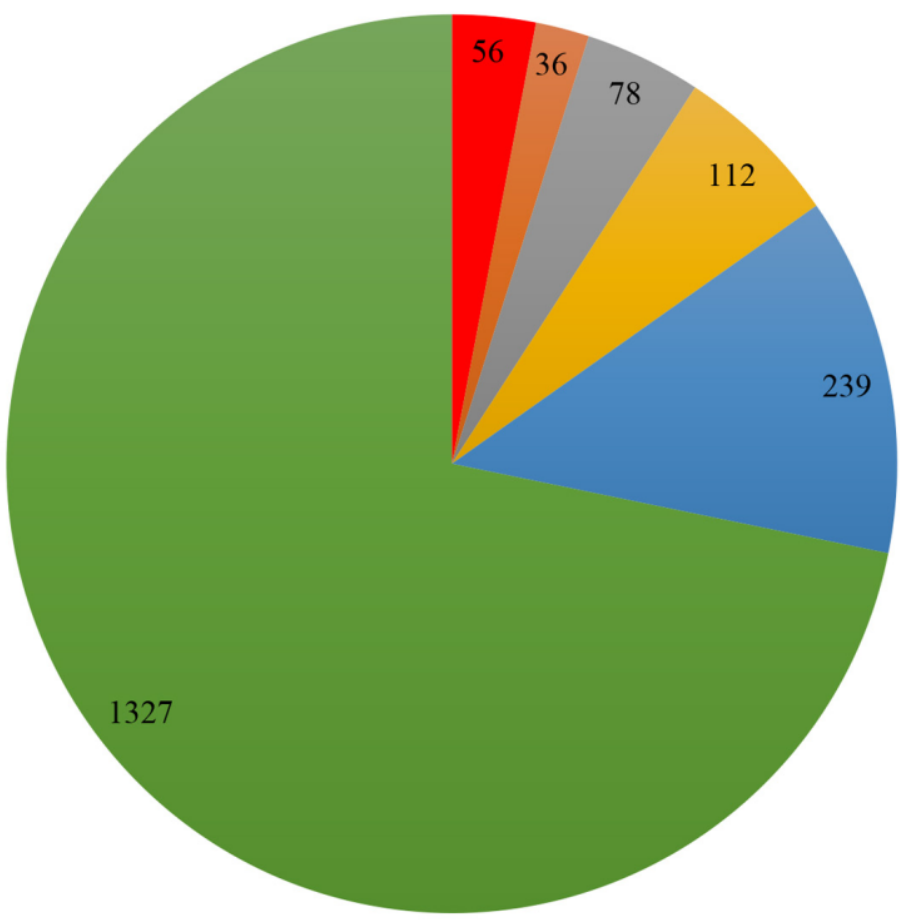

- Mild or moderate developed to severe (56)

- Fever over $38.5^{\circ} \mathrm{C}$ for three days in shelter hospital (36)

घ Comorbidity with cancer or severe

liver/kidney/heart disease (78)

- Mental illness or tremendous mental pressure or pregnant woman (112)

- persistent positive nucleic acid testing (239)

- Reached the criteria of isolation release or discharge(1327)

Figure 1. Outcome and distribution of all enrolled patients in Jianghan Fangcang shelter hospital (1848). 
Table 1. Clinical characteristics of patients transferring to the designated hospitals from fangcang shelter hospital.

\begin{tabular}{|c|c|c|c|c|c|}
\hline & $\begin{array}{c}\text { Mild or } \\
\text { moderate } \\
\text { progressed to } \\
\text { severe (56) } \\
\end{array}$ & $\begin{array}{c}\text { Fever over } \\
38.5^{\circ} \mathrm{C} \text { for three } \\
\text { days in shelter } \\
\text { hospital (36) } \\
\end{array}$ & $\begin{array}{c}\text { Comorbidity with } \\
\text { cancer or severe } \\
\text { liver/kidney/heart } \\
\text { disease (78) } \\
\end{array}$ & $\begin{array}{c}\text { Mental illness, } \\
\text { mental pressure or } \\
\text { pregnant woman } \\
(112)\end{array}$ & $\begin{array}{c}\text { Persistent } \\
\text { positive } \\
\text { nucleic acid } \\
\text { testing (239) }\end{array}$ \\
\hline Age & $55(48-61)$ & $52(44-58)$ & $62(52-64)$ & $54(48-62)$ & $53(45-61)$ \\
\hline Female sex & $26(46.4 \%)$ & $22(61.1 \%)$ & $58(74.4 \%)$ & $47(42.0 \%)$ & $132(55.2 \%)$ \\
\hline $\begin{array}{l}\text { Median incubation } \\
\text { (onset to cabin) } \\
\text { period }\end{array}$ & $10(8-16)$ & $12(6-13)$ & $12(10-23)$ & $12(7-18)$ & $13(9-19)$ \\
\hline $\begin{array}{l}\text { Median cabin } \\
\text { period }\end{array}$ & $4(3-8)$ & $7(4-12)$ & $17(13-22)$ & $16(12-21)$ & $18(14-22)$ \\
\hline $\begin{array}{l}\text { Median incubation } \\
\text { (onset to transfer) } \\
\text { period }\end{array}$ & $15(12-23)$ & $20(11-25)$ & $30(29-37)$ & $19(17-26)$ & $31(25-37)$ \\
\hline \multicolumn{6}{|l|}{$\begin{array}{l}\text { Fever on cabin } \\
\text { admission }\end{array}$} \\
\hline Patients & $43(76.8 \%)$ & $24(67.7 \%)$ & $16(20.5 \%)$ & $52(46.4 \%)$ & $88(36.8 \%)$ \\
\hline $\begin{array}{l}\text { Median temperature } \\
\text { (of peak value) } \\
\text { Symptoms } \\
\text { at onset }\end{array}$ & \multicolumn{4}{|c|}{$\begin{array}{l}\text { Symptoms } \\
\text { at onset }\end{array}$} & $38.2 \pm 0.53$ \\
\hline Cough & $34(60.7 \%)$ & $18(50.0 \%)$ & $33(42.3 \%)$ & $50(44.6 \%)$ & $88(36.8 \%)$ \\
\hline Sputum production & $3(5.4 \%)$ & $1(2.8 \%)$ & $5(6.4 \%)$ & $8(7.1 \%)$ & $15(6.3 \%)$ \\
\hline Nasal congestion & $4(7.1 \%)$ & $1(2.8 \%)$ & $3(3.8 \%)$ & $9(8.0 \%)$ & $13(5.4 \%)$ \\
\hline Sore throat & $11(19.6 \%)$ & $6(16.7 \%)$ & $10(12.8 \%)$ & $14(12.5 \%)$ & $31(13.0 \%)$ \\
\hline $\begin{array}{l}\text { Shortness } \\
\text { of breath }\end{array}$ & $10(17.9 \%)$ & $6(16.7 \%)$ & $10(12.8 \%)$ & $16(14.3 \%)$ & $29(12.1 \%)$ \\
\hline Stomach ache & $1(1.8 \%)$ & 0 & $1(1.3 \%)$ & $2(1.8 \%)$ & $5(2.1 \%)$ \\
\hline Chest pain & $5(8.9 \%)$ & $3(8.3 \%)$ & $6(7.7 \%)$ & $8(7.1 \%)$ & $17(7.1 \%)$ \\
\hline Chest congestion & $10(17.9 \%)$ & $3(8.3 \%)$ & $8(10.3 \%)$ & $13(11.6 \%)$ & $32(13.4 \%)$ \\
\hline $\begin{array}{l}\text { Nausea } \\
\text { or vomiting }\end{array}$ & $4(7.1 \%)$ & $1(2.8 \%)$ & $5(6.4 \%)$ & $7(6.3 \%)$ & $10(4.2 \%)$ \\
\hline Diarrhea & $11(19.6 \%)$ & $5(13.9 \%)$ & $20(12.8 \%)$ & $18(16.1 \%)$ & $16(6.7 \%)$ \\
\hline $\begin{array}{l}\text { Myalgia } \\
\text { or arthralgia }\end{array}$ & $17(30.4 \%)$ & $9(25.0 \%)$ & $18(25.6 \%)$ & $30(26.8 \%)$ & $60(25.1 \%)$ \\
\hline Poor appetite & $16(28.6 \%)$ & $9(25.0 \%)$ & $17(21.8 \%)$ & $27(24.1 \%)$ & $57(23.8 \%)$ \\
\hline Headache & $2(3.6 \%)$ & $2(5.6 \%)$ & $2(2.6 \%)$ & $3(2.7 \%)$ & $11(4.6 \%)$ \\
\hline Fatigue & $32(57.1 \%)$ & $20(55.6 \%)$ & $37(47.4 \%)$ & $52(46.4 \%)$ & $71(29.7 \%)$ \\
\hline Chills & $5(8.9 \%)$ & $3(8.3 \%)$ & $4(5.1 \%)$ & $8(7.1 \%)$ & $18(7.5 \%)$ \\
\hline Palmic & $2(3.6 \%)$ & $1(2.8 \%)$ & $1(1.3 \%)$ & $2(1.8 \%)$ & $10(4.2 \%)$ \\
\hline Perspire & $1(1.8 \%)$ & 0 & $1(1.3 \%)$ & $1(0.9 \%)$ & $3(1.3 \%)$ \\
\hline \multicolumn{6}{|l|}{ Comorbidity } \\
\hline Any & $23(41.1 \%)$ & $14(38.9 \%)$ & $78(100 \%)$ & $49(43.8 \%)$ & $82(34.3 \%)$ \\
\hline $\begin{array}{l}\text { Chronic obstructive } \\
\text { pulmonary disease }\end{array}$ & $1(1.8 \%)$ & $1(2.8 \%)$ & $10(12.8 \%)$ & $2(1.8 \%)$ & $6(2.5 \%)$ \\
\hline Diabetes & $4(7.1 \%)$ & $2(5.6 \%)$ & $16(20.5 \%)$ & $8(7.1 \%)$ & $13(5.4 \%)$ \\
\hline Hypertension & $13(23.2 \%)$ & $7(19.4 \%)$ & $25(32.1 \%)$ & $27(24.1 \%)$ & $45(18.8 \%)$ \\
\hline $\begin{array}{l}\text { Coronary } \\
\text { heart disease }\end{array}$ & $4(7.1 \%)$ & $2(5.6 \%)$ & $9(11.5 \%)$ & $8(7.1 \%)$ & $11(5.3 \%)$ \\
\hline $\begin{array}{l}\text { Cerebrovascular } \\
\text { disease }\end{array}$ & $1(1.8 \%)$ & $1(2.8 \%)$ & $9(11.5 \%)$ & $2(1.8 \%)$ & $4(1.7 \%)$ \\
\hline $\begin{array}{l}\text { Chronic renal } \\
\text { disease }\end{array}$ & $1(1.8 \%)$ & 0 & $9(11.5 \%)$ & $2(1.8 \%)$ & $3(1.3 \%)$ \\
\hline
\end{tabular}

Data are median (IQR), $\mathrm{n}(\%)$ or $\mathrm{n} / \mathrm{N}(\%)$. 
Table 2. Clinical characteristics of the mild or moderate progressed to severe patients.

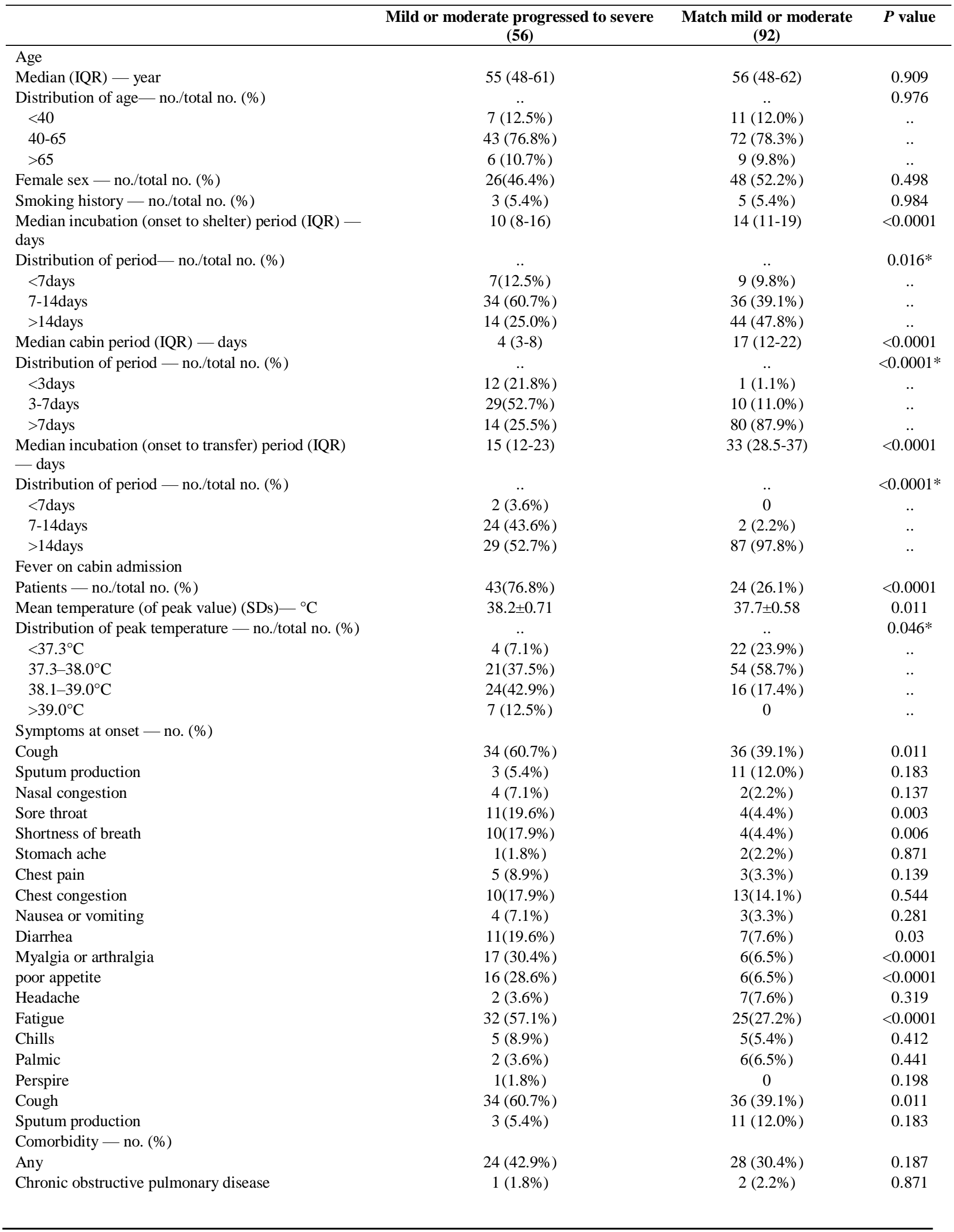


Data are mean (SDs), median (IQR), $\mathrm{n}(\%)$, or $\mathrm{n} / \mathrm{N}(\%)$. P values were calculated by Student $\mathrm{t}$ test, Mann-Whitney $\mathrm{U}$ test, $\chi^{2}$ test, or Fisher's exact test, as appropriate. ${ }^{*} \chi^{2}$ test comparing all subcategories.

Table 3. Radiographic, laboratory findings, treatments, and clinical outcomes.

\begin{tabular}{|c|c|c|c|}
\hline & $\begin{array}{c}\text { Mild or moderate } \\
\text { progressed } \\
\text { to severe }(56)\end{array}$ & $\begin{array}{l}\text { Match mild or moderate } \\
(92)\end{array}$ & P value \\
\hline \multicolumn{4}{|l|}{ Radiologic findings } \\
\hline \multicolumn{4}{|l|}{ Abnormalities on chest $\mathrm{CT}-$ no./total no. (\%) } \\
\hline Local & $22(39.3 \%)$ & $10(10.9 \%)$ & $<0.0001$ \\
\hline Multiple & $11(19.6 \%)$ & $52(56.5 \%)$ & $<0.0001$ \\
\hline Bilateral & $24(42.9 \%)$ & $72(78.3 \%)$ & $<0.0001$ \\
\hline Unilateral & $7(12.5 \%)$ & $18(19.6 \%)$ & 0.374 \\
\hline Patchy shadowing & $10(17.9 \%)$ & $7(7.6 \%)$ & 0.034 \\
\hline Ground-glass opacity & $53(94.6 \%)$ & $82(89.1 \%)$ & 0.432 \\
\hline Interstitial abnormalities & $1(1.8 \%)$ & $19(20.7 \%)$ & 0.002 \\
\hline \multicolumn{4}{|l|}{ Laboratory findings } \\
\hline White-cell count, median $(\mathrm{IQR}), \times 10^{9}$ per $\mathrm{L}$ & $5.75(4.66-7.91)$ & $5.96(5.04-7.09)$ & 0.848 \\
\hline Lymphocyte count, mean (SDs), $\times 10^{9}$ per L & $1.70 \pm 0.72$ & $1.88 \pm 0.54$ & 0.244 \\
\hline $\begin{array}{l}\text { Distribution of lymphocyte count- no./total no. } \\
(\%)\end{array}$ & 42 & 90 & 0.468 \\
\hline$<1.5 \times 10^{9}$ per $\mathrm{L}$ & $15(35.7 \%)$ & $24(26.7 \%)$ & .. \\
\hline$\geq 1.5 \times 10^{9}$ per $\mathrm{L}$ & $27(64.3 \%)$ & $66(73.3 \%)$ & .. \\
\hline Platelet count, median $(\mathrm{IQR}), \times 10^{9}$ per $\mathrm{L}$ & $238(181-331)$ & $244(205-320)$ & 0.724 \\
\hline Distribution of platelet count - no./total no. (\%) & 42 & 90 & 0.183 \\
\hline$<150 \times 10^{9}$ per $\mathrm{L}$ & $2(4.8 \%)$ & $1(1.1 \%)$ & .. \\
\hline$\geq 150 \times 10^{9}$ per $\mathrm{L}$ & $40(95.2 \%)$ & $89(98.9 \%)$ & .. \\
\hline Median hemoglobin $(\mathrm{IQR})$ - g per dl & $134(131-147)$ & $137(128-144)$ & 0.828 \\
\hline C-reactive protein, median (IQR), mg per L & $10.12(1.33-16.44)$ & $1.14(0.37-2.61)$ & $<0.0001$ \\
\hline Distribution - no./total no. $(\%)$ & 42 & 90 & $<0.0001 *$ \\
\hline C-reactive protein $\geq 10 \mathrm{mg}$ per $\mathrm{L}$ & $14(33.3 \%)$ & $5(5.6 \%)$ &.. \\
\hline C-reactive protein $<10 \mathrm{mg}$ per $\mathrm{L}$ & $28(66.7 \%)$ & $85(94.4 \%)$ & .. \\
\hline Treatments & 42 & 90 & .. \\
\hline $\begin{array}{l}\text { Antibiotics, antivirus and traditional Chinese } \\
\text { medicine }\end{array}$ & $16(38.1 \%)$ & $40(50.6 \%)$ & 0.188 \\
\hline Antibiotics and antivirus & $5(11.9 \%)$ & $3(3.9 \%)$ & 0.091 \\
\hline Antivirus and traditional Chinese medicine & $6(14.3 \%)$ & $17(21.8 \%)$ & 0.319 \\
\hline \multicolumn{4}{|l|}{ Clinical outcomes at data cutoff $(2020.3 .12)$} \\
\hline Nucleic acid test & 52 & 92 & 0.106 \\
\hline Positive & $3(5.8 \%)$ & $1(1.1 \%)$ &.. \\
\hline Negative & $49(94.2 \%)$ & $91(98.9 \%)$ & .. \\
\hline CT scan & .. & & $<0.0001 *$ \\
\hline Recovery & $2(3.8 \%)$ & $2(2.2 \%)$ &.. \\
\hline Improved & $48(92.3 \%)$ & $90(97.8 \%)$ & .. \\
\hline Deterioration or new lesions & $2(3.8 \%)$ & 0 & .. \\
\hline
\end{tabular}

Data are mean (SDs), median (IQR), $\mathrm{n}(\%)$, or $\mathrm{n} / \mathrm{N}(\%)$. P values were calculated by Student $\mathrm{t}$ test, Mann-Whitney $\mathrm{U}$ test, $\chi^{2}$ test, or Fisher's exact test, as appropriate. ${ }^{*} \chi^{2}$ test comparing all subcategories. 

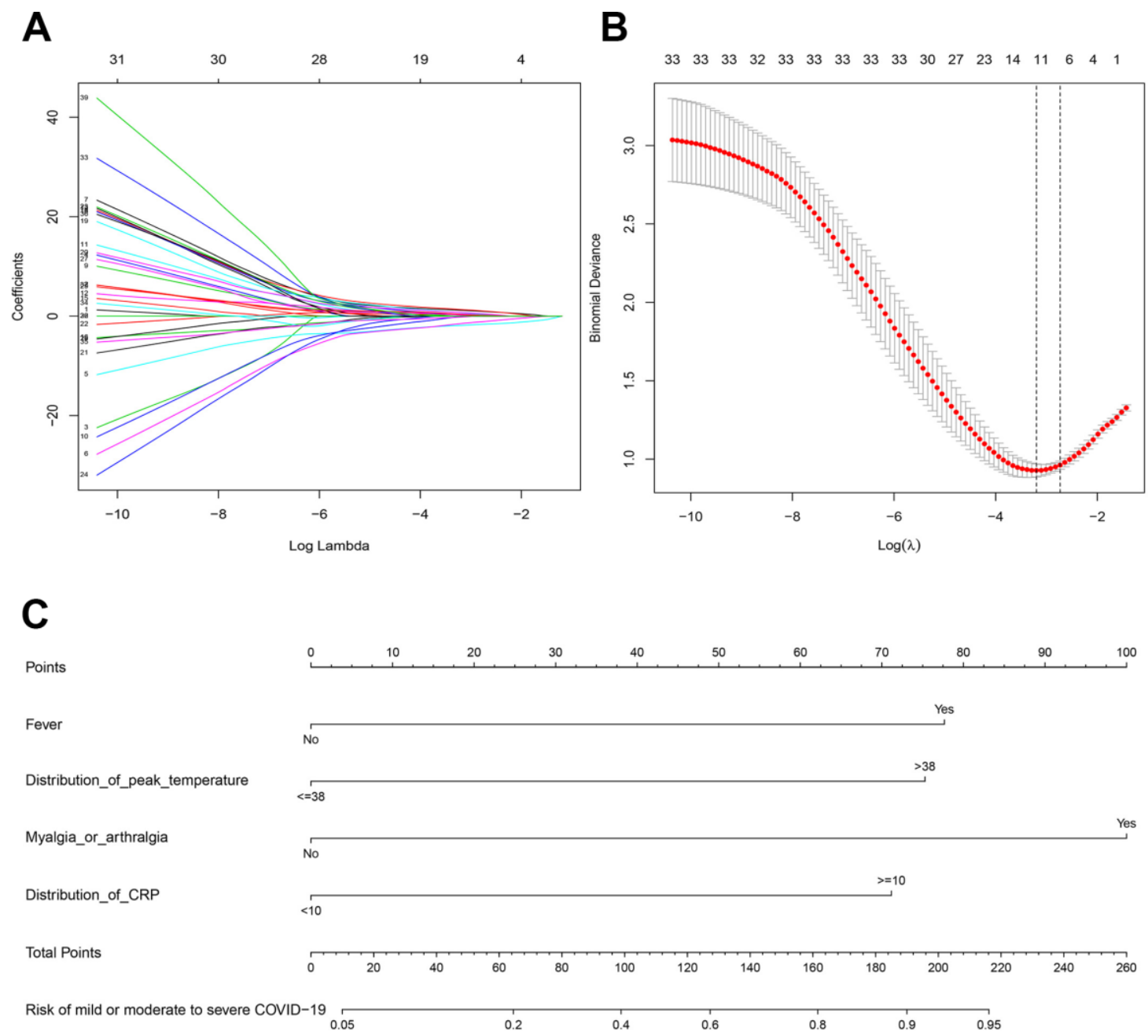

D

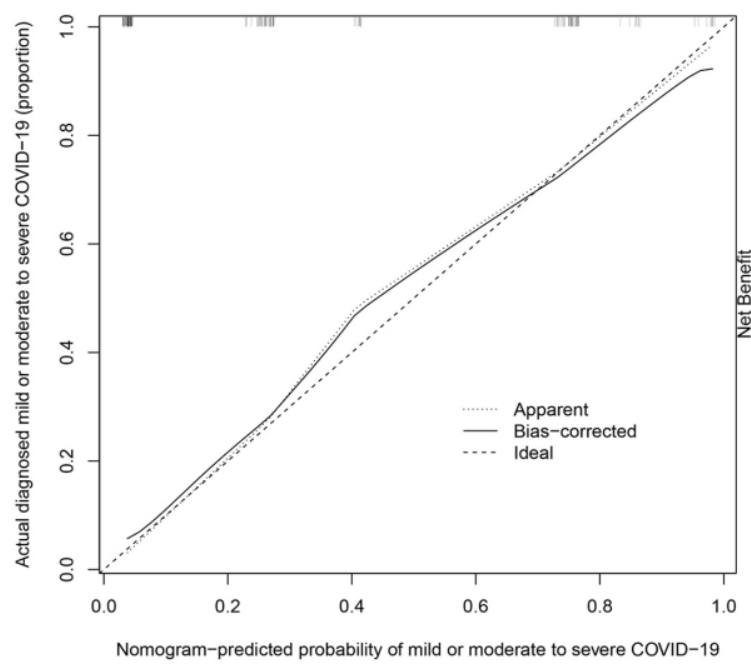

$\mathbf{E}$

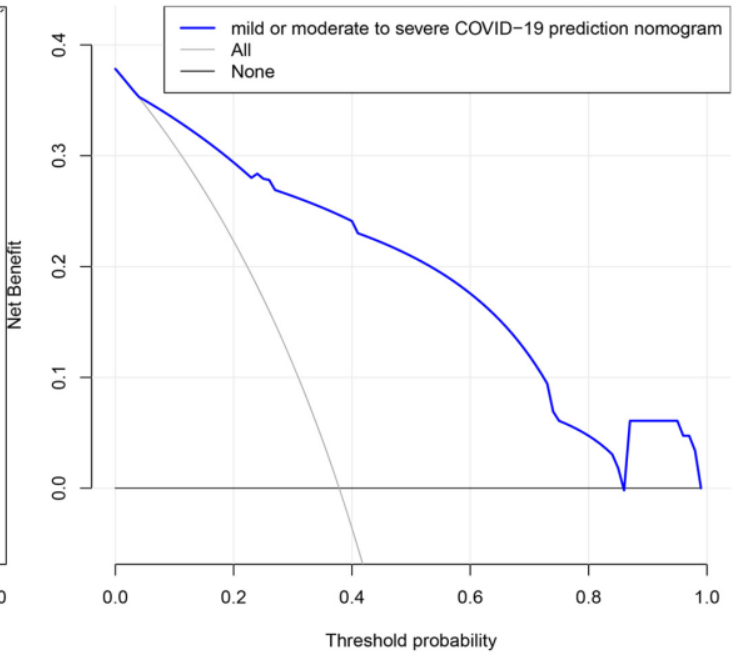

Figure 2. Prognostic factor selection using the LASSO binary logistic regression model. (A) LASSO coefficient profiles of the 45 variables. (B) Optimal parameter (lambda) selection in the LASSO model used tenfold cross-validation via minimum criteria. The partial likelihood deviance (binomial deviance) curve was plotted versus log(lambda). Dotted vertical lines were drawn at the optimal values by using the minimum criteria and the one standard error of the minimum criteria. (C) Developed mild or moderate to severe COVID-19 nomogram. (D) Calibration plot. (E) Decision curve. 
by bootstrapping validation. In this risk nomogram, effective performance showed a good prediction capability. Furthermore, the decision curve demonstrated that the prediction nomogram had superior standardized net benefit while the threshold probability of a patient and a doctor is $4 \%$ and $83 \%$, respectively (Figure 2E).

Furthermore, by utilizing receiver operating characteristic (ROC) analysis, we compared the predictive value of our prediction model for incidence of severe illness with that of the MuLBSTA, CURB-6 and NLR models. The analysis revealed that our prediction nomogram had the highest area under curve (AUC) (0.902) than the other three models (Supplementary Figure 1).

\section{DISCUSSION}

It is the first time to observed dynamically and comprehensively disclose the clinical characteristics and prognostic factors of COVID-19 patient progression to severe. The number of patients with severe type determines the final mortality rate of COVID-19. In this study, the case-severity rate was observed with a relatively large prospective cohort, which might be a valuable complement to the characteristics of COVID19. In the Fangcang shelter hospital of Jianghan, about $3.0 \%$ of the patients transformed to severe, which was significantly lower than the $14 \%$ cases classified as severe or critical in the spectrum of COVID-19 disease $[7,8]$. The most common symptom at admission was fever and $76.8 \%$ (43/56 cases) mild to severe patients got fever on cabin admission. However, some patients with Covid-19 did not have fever abnormalities on initial presentation, which has complicated the diagnosis [9]. In this study, 55.4\% patients were with peek temperature more than $38.0^{\circ} \mathrm{C}$, while $12.5 \%$ of patients were once with fever over $39.0^{\circ} \mathrm{C}$. High fever was associated with the development of severity and critical death [10-12]. Therefore, keep vigilance of those mild patients whose peak temperature over $38.0^{\circ} \mathrm{C}$. They were quickly transferred to the designated higher-level hospitals once the blood oxygen saturation of those patients was less than 93\% in Fangcang shelter hospital of Jianghan.

For more specialized monitoring, chest imaging and laboratory services were applied in the Fangcang shelter hospitals. Ground-glass opacity $(53 / 56,94.6 \%)$ was the most common morphological depiction in CT scan on admission. However, only $19.6 \%$ of patients showed multiple lesions, $42.9 \%$ patients presented bilateral lesions. Compared with mild patients, most severe patients took CT scan in this study within seven days. The lesions that were present in asymptomatic individuals progressed to bilateral diffuse disease with consolidation around day 10 after the symptom onset [13-15]. The predominant CT pattern was unilateral and multifocal ground-glass opacities in early stage, then lesions quickly evolved to bilateral, diffuse groundglass opacity in later stage [13]. However, those characteristics were not consistent with what we had expected in this study. Therefore, the value of lung CT in determining the prognosis of mild COVID-19 patients still needs further research. Meanwhile, most of the patients had elevated levels of CRP at ill onset with $33.3 \%$ over $10 \mathrm{mg} / \mathrm{L}$. Similarly, compared to mild or moderate cases, severe cases more frequently had higher levels of CRP $[9,16,17]$. Therefore, imaging and laboratory results could contribute to make the quick decision of transferring to the designated hospitals.

Previously, older age (over 65 years) was associated with higher odds of progression to severity of COVID19, which also has been reported as an important independent predictor of mortality in SARS and MERS [18-20]. In order to better display the clinical characteristics of mild or moderate to severe patients below 65 years old, 92 age-and sex-matched mild or moderate patients stayed in the Fangcang shelter hospital at the same time. In this study, several factors in adults who were hospitalized in Fangcang shelter hospital were associated with mild progressed to severe COVID-19. In particular, patients aged 40-65 years constituted the highest proportion within the severe group in this study. It had reported that $75 \%$ of COVID19 death cases previously suffered 1-2 underlying diseases, a majority of which were diabetes and cardiovascular diseases [21]. In line with above evidence, our study also found that $42.9 \%$ of the mild to severe patients had 1-2 basic diseases, such as cardiovascular diseases, cerebrovascular diseases and endocrine system diseases.

Notably, several clinical manifestations were identified as prognostic factors for progression from mild to severe in the univariate logistic regression analysis. We found that myalgia or arthralgia on admission was associated with increased odds of mild to severe (Table 4). Furthermore, $30.4 \%$ patients had the myalgia or arthralgia. Less common symptoms include poor appetite, sore throat and shortness of breath. However, respiratory system affection remained as the primary symptom [9, 22, 23]. Overall, onset of fever and myalgia or arthralgia symptoms should be closely monitored among cabin hospital, more attention should also be paid to patients on those isolation patients at home.

In this study, we developed a prediction nomogram included fever, distribution of peak temperature 
Table 4. Risk factors associated with mild or moderate pregressed to severe transfer from fangcang shelter hospital to the designated hospital.

\begin{tabular}{lccc}
\hline Logistic Regress Variables & $\boldsymbol{\beta}$ & Multivariable OR (CI 95\%) & P Value \\
\hline Median incubation (onset to shelter) period $(\leq 14 \mathrm{VS} \geq 14$ days) & -0.529 & $0.588(0.158-2.076)$ & 0.412 \\
Fever on shelter admission (Patients - no./total no. $(\%))$ & 2.599 & $13.459(4.147-54.650)$ & $<0.0001^{*}$ \\
Distribution of peak temperature $\left(\leq 38^{\circ} \mathrm{C}\right.$ VS $\left.>38^{\circ} \mathrm{C}\right)$ & 2.421 & $11.261(3.405-43.737)$ & $<0.0001^{*}$ \\
Sputum production & -1.127 & $0.324(0.051-1.697)$ & 0.195 \\
Sore throat & 1.929 & $6.884(0.977-77.611)$ & 0.081 \\
Shortness of breath & 1.706 & $5.506(0.798-50.485)$ & 0.096 \\
Myalgia or arthralgia & 2.665 & $14.375(3.223-83.279)$ & $0.001^{*}$ \\
Poor appetite & 1.335 & $3.802(0.785-21.792)$ & 0.111 \\
Headache & -2.179 & $0.113(0.007-1.082)$ & 0.083 \\
Diabetes & 1.273 & $3.570(0.298-48.145)$ & 0.318 \\
Distribution of CRP $(<10 \mathrm{VS} \geq 10$ per L) & 2.254 & $9.530(2.145-49.634)$ & $0.004^{*}$ \\
\hline
\end{tabular}

$B$ is the regression coefficient. $\mathrm{OR}=$ odds ratio. $\mathrm{Cl}$, confidence interval. *Statistically significant.

$\left(>38^{\circ} \mathrm{C}\right)$, myalgia or arthralgia and distribution of $\mathrm{C}$ reactive protein $(\geq 10$ per $\mathrm{L}$ ) for patients with mild or moderate to severe COVID-19. Previous studies suggested that both MuLBSTA score and CURB-65 score were widely used to assess the mortality of pneumonia [24-26]. Moreover, a recent study had confirmed that neutrophil-to-lymphocyte ratio (NLR) could predicts severe illness patients with COVID-19 [27]. However, compared with the above three models, our prediction nomogram model seemed to have a higher C-index and AUC than them. Additionally, our model seems to be more clinical significance. Because we can predict the incidence of patients with COVID-19 from mild to severe. And the other three models mainly predict the mortality rate. Therefore, our model can play a warning role in the early stages of disease. According to the results, we suggested that patients with fever (peak temperature over $38.0^{\circ} \mathrm{C}$ ), myalgia or arthralgia and CRP more than 10 per $\mathrm{L}$ should be vigilant by doctors and nurses in Fangcang shelter hospital.

There were some limitations in this study. Firstly, due to limited medical resources in Fangcang shelter hospital, not all laboratory tests have been performed, such as lactate dehydrogenase, IL-6, and serum ferritin. Secondly, the study was limited to the patients with mild or moderate infection in a single center study. Thirdly, duo to the shortage of medical resource in Wuhan, we could not track the patients who developed severe COVID-19 after transfer point in Fangcang shelter hospital. Thus, the result of $3.6 \%$ severe progression rate might be inaccurate. However, the study population is representative of cases mild developed to severe in Wuhan. To the best of our knowledge, this is the largest retrospective cohort study to observed dynamically and comprehensively disclose the clinical characteristics and risk factors for developed COVID-19 patients to severe type. The distribution of peak temperature $\left(>38^{\circ} \mathrm{C}\right)$ on set, myalgia or arthralgia and C-reactive protein $(\geq 10 \mathrm{mg}$ per L) were the prognostic factors to identify the progression of COVID-19 patients with mild or moderate type. Early intervention in these risk factors may effectively control the development of the COVID19. Overall, Fangcang shelter hospitals had substantially reduced the time from the onset of severe symptoms to admission to the designated hospital, compared with the alternative of home isolation [28, 29]. We believe that the information in the article will provide valuable data for other countries facing the COVID-19 pandemic, when they are establishing the national public health emergency management for COVID- 19 .

\section{MATERIALS AND METHODS}

\section{Patient enrollment}

The Jianghan Fangcang shelter hospital opened on the $5^{\text {th }} \mathrm{Feb}$ and closed on the $9^{\text {th }}$ Mar 2020. During this period, a total of 1848 cases with COVID-19 were enrolled in Jianghan Fangcang shelter hospital of Wuhan from Feb 5th to Mar 9th, 2020. The admission criteria of Fangcang shelter hospital were COVID-19 patients with mild or moderate type. Diagnosis of COVID-19 was based on the National health commission (NHC) of the People's Republic of China [30]. The clinical classifications are as follows: (1) mild, the clinical symptoms are mild and no pneumonia manifestation can be found in imaging; (2) moderate, patients have symptoms like fever and respiratory tract symptoms, etc. and pneumonia manifestation can be seen in imaging; (3) severe, meet any of the following conditions: a) respiratory distress, respiratory rate $\geq 30$ breaths / min; $b$ ) the oxygen saturation $\leq 93 \%$ at a rest state; c) arterial partial pressure of oxygen/ oxygen concentration ( $\mathrm{FiO} 2)$ $\leq 300 \mathrm{mmHg}(1 \mathrm{mmHg}=0.133 \mathrm{kPa})$; d $)$ pulmonary imaging with $>50 \%$ lesions progression within 24 to 48 
hours. The release of isolation and discharge standards are as follows: (1) with normal body temperature for more than 3 days; (2) with significantly recovered respiratory symptoms; (3) lung imaging shows obvious absorption and recovery of acute exudative lesion; (4) with negative results of the nucleic acid tests of respiratory pathogens for consecutive two times (sampling interval at least 1 day). Only reaching above four standards can these patients be released.

This study was approved by the Research Ethics Commission of Wuhan Union Hospital ([2020]0038) and informed consent was waived by the Ethics Commission of Wuhan Union Hospital for emerging infectious diseases.

\section{Baseline data collection}

Before admission into Fangcang shelter hospital, all suspected patients of COVID-2019 were taken upper respiratory throat swab samples. Chest CT scan was performed as well. Clinical and laboratory findings were recorded and carefully checked. Laboratory tests included biochemical Indicators, blood routine, and Creactive protein (CRP, normal range $0-4 \mathrm{mg}$ per $\mathrm{L}$ ). Epidemiological history, comorbidity, vital signs, symptoms and signs were recorded in detail. Patients meeting the diagnosis of mild or moderate type were admitted to the Fangcang shelter hospital. Two reviewers (HW, JH) independently checked all collected data. In case of disagreement among two reviewers, consensus was conducted by a third reviewer (YW).

\section{Follow-up}

During the following days in Fangcang shelter hospital, the patients were re-examined for laboratory and imaging examination, and recorded symptoms, signs, treatments and outcome events. The throat swab specimens of RT-PCR test and chest CT scan were performed according to the symptoms and signs. After admission, all patients were given antiviral therapy (e.g., abidor hydrochloride) and other individualized treatments (such as antibiotics, antihypertensive and hypoglycemic therapy) according to the doctor's advice and NHC's interim guidelines [7]. The clinical outcomes of patients in the Fangcang shelter hospital were divided into three ways. They were the patients transferred to the designated hospitals for further treatments, the patients reaching the criteria of isolation release, and the patients kept treatment in the mobile cabin.

\section{COVID-19 nucleic acid detection and chest CT scan}

Throat swab samples were stored in virus transport medium and transported to Wuhan Union Hospital for laboratory diagnosis. Throat swab specimens of all patients were subject to real time PCR tests by amplifying ORF1ab gene and $\mathrm{N}$ gene of SARS-CoV-2 (BioGerm, Shanghai, China). The CT examinations were carried out with a 16-row multidetector CT scanner $(\mu \mathrm{CT} 550$, Shanghai LianYing medical technology co., LTD) using the following parameters: detector collimation widths $64 \times 0.6 \mathrm{~mm}, 128 \times 0.6 \mathrm{~mm}$, $64 \times 0.6 \mathrm{~mm}$, and $64 \times 0.6 \mathrm{~mm}$; and tube voltage $120 \mathrm{kV}$.

\section{Statistical analysis}

Continuous variables were represented by mean (standard deviations, SDs) or median (interquartile range, IQR) as appropriate, categorical variables were described as number (\%). Significant differences between the 2 groups (mild patients and mild to severe patients) were compared by Student $t$ test, MannWhitney U test, chi-square or Fischer exact test where appropriate. In addition, we also used least absolute shrinkage and selection operator (LASSO) method to select the optimal predictive features in risk factors from the patients with COVID-19, and features with nonzero coefficients were selected in the LASSO model. Then, multivariable logistic regression model was used to build a predicting model by incorporating the features selected in the LASSO regression model. The variables with the $P$-value less than 0.05 were included in this model. The results were present as odds ratio (OR) [95\% confidence interval]. Because all tests were two-sided, $P$ value less than 0.05 was considered statistically significant. Analyses were performed using SPSS 20.0 statistical package and R version 3.6.0 was used to build nomogram, calibration and decision curve.

\section{AUTHOR CONTRIBUTIONS}

HS designed the study and had full access to all of the data in the study and was responsibility for the integrity of the data and the accuracy of the data analysis. HW, JH, YW, ZW, XC, CY and XF collected data. YL, YF and $\mathrm{BW}$ analyzed data. YL and YF wrote the article. All authors critically revised the manuscript for important content and gave final approval for the version to be published.

\section{ACKNOWLEDGMENTS}

The Jianghan Fangcang shelter hospital was managed daily by Union Hospital, Tongji Medical College, Huazhong University of Science and Technology and twenty-one medical teams from other provinces associated with six local hospitals participated in the work. We thank 1573 staff in the Jianghan Fangcang shelter hospital, including 308 doctors, 872 nurses, 120 
medical technician, 16 hospital infection-control staff and 257 administrative logistical staff.

\section{CONFLICTS OF INTEREST}

We declare no conflicts of interest.

\section{FUNDING}

No specific grant from any funding was applied to this research.

\section{REFERENCES}

1. The Lancet. COVID-19: too little, too late? Lancet. 2020; 395:755.

https://doi.org/10.1016/S0140-6736(20)30522-5

PMID: 32145772

2. National Health Commission of the People's Republic of China. Updates on the epidemic (in Chinese). 2020. http://www.nhc.gov.cn/xcs/yqtb/202003/bf66696029 ba420098164607240074f8.Shtml.

3. Chen S, Zhang Z, Yang J, Wang J, Zhai X, Bärnighausen $T$, Wang C. Fangcang shelter hospitals: a novel concept for responding to public health emergencies. Lancet. 2020; 395:1305-14.

https://doi.org/10.1016/S0140-6736(20)30744-3 PMID: $\underline{32247320}$

4. COVID-19 Emergency Response Key Places Protection and Disinfection Technology Team, Chinese Center for Disease Control and Prevention. [Health protection guideline of mobile cabin hospitals during COVID-19 outbreak]. Zhonghua Yu Fang Yi Xue Za Zhi. 2020; 54:357-359.

https://doi.org/10.3760/cma.j.cn112150-20200217$\underline{00121}$

PMID:32268641

5. The National Health Commission of the People's Republic of China. Manual for working in Fangcang shelter hospitals (3rd ed; in Chinese). 2020. https://mp.weixin.qq.com/s/va9vs4HuP8wRQM5fALQ crg

6. Yao G, Zhang X, Wang H, Li J, Tian J, Wang L. Practice and thinking of the informationized cabin hospitals during the novel coronavirus pneumonia period (in Chinese). Chin J Hosp Adm. 2020.

7. Wu Z, McGoogan JM. Characteristics of and important lessons from the coronavirus disease 2019 (COVID-19) outbreak in China: summary of a report of 72314 cases from the Chinese center for disease control and prevention. JAMA. 2020. [Epub ahead of print]. https://doi.org/10.1001/jama.2020.2648 PMID:32091533
8. Linton NM, Kobayashi $T$, Yang $Y$, Hayashi $K$, Akhmetzhanov AR, Jung SM, Yuan B, Kinoshita R, Nishiura $H$. Incubation period and other epidemiological characteristics of 2019 novel coronavirus infections with right truncation: a statistical analysis of publicly available case data. J Clin Med. 2020; 9:538.

https://doi.org/10.3390/icm9020538 PMID:32079150

9. Guan WJ, Ni ZY, Hu Y, Liang WH, Ou CQ, He JX, Liu L, Shan $\mathrm{H}$, Lei $\mathrm{CL}$, Hui DS, Du B, Li L, Zeng G, et al, and China Medical Treatment Expert Group for Covid-19. Clinical characteristics of coronavirus disease 2019 in China. N Engl J Med. 2020; 382:1708-20. https://doi.org/10.1056/NEJMoa2002032 PMID:32109013

10. Bhatraju PK, Ghassemieh BJ, Nichols M, Kim R, Jerome KR, Nalla AK, Greninger AL, Pipavath S, Wurfel MM, Evans L, Kritek PA, West TE, Luks A, et al. Covid-19 in critically ill patients in the seattle region - case series. $\mathrm{N}$ Engl J Med. 2020; 382:2012-22.

https://doi.org/10.1056/NEJMoa2004500 PMID:32227758

11. Wu C, Chen X, Cai $Y$, Xia J, Zhou X, Xu S, Huang H, Zhang L, Zhou X, Du C, Zhang Y, Song J, Wang S, et al. Risk Factors Associated With Acute Respiratory Distress Syndrome and Death in Patients With Coronavirus Disease 2019 Pneumonia in Wuhan, China. JAMA Intern Med. 2020; 180:1-11. https://doi.org/10.1001/jamainternmed.2020.0994 PMID:32167524

12. Yang $X, Y u Y, X u$ J, Shu H, Xia J, Liu H, Wu Y, Zhang L, Yu $Z$, Fang $M, Y u T$, Wang $Y$, Pan $S$, et al. Clinical course and outcomes of critically ill patients with SARS-CoV-2 pneumonia in Wuhan, China: a single-centered, retrospective, observational study. Lancet Respir Med. 2020; 8:475-81.

https://doi.org/10.1016/S2213-2600(20)30079-5 PMID: $\underline{2105632}$

13. Pan $F$, Ye $T$, Sun $P$, Gui $S$, Liang $B$, Li L, Zheng D, Wang J, Hesketh RL, Yang L, Zheng C. Time course of lung changes at chest $C T$ during recovery from coronavirus disease 2019 (COVID-19). Radiology. 2020; 295:715-21.

https://doi.org/10.1148/radiol.2020200370 PMID:32053470

14. Shi H, Han X, Jiang N, Cao Y, Alwalid O, Gu J, Fan Y, Zheng $C$. Radiological findings from 81 patients with COVID-19 pneumonia in Wuhan, China: a descriptive study. Lancet Infect Dis. 2020; 20:425-34. https://doi.org/10.1016/S1473-3099(20)30086-4 PMID:32105637

15. Lee EY, Ng MY, Khong PL. COVID-19 pneumonia: what has CT taught us? Lancet Infect Dis. 2020; 20:384-85. 
https://doi.org/10.1016/S1473-3099(20)30134-1 PMID:32105641

16. Huang $C$, Wang $Y$, Li $X$, Ren $L$, Zhao J, Hu Y, Zhang L, Fan G, Xu J, Gu X, Cheng Z, Yu T, Xia J, et al. Clinical features of patients infected with 2019 novel coronavirus in Wuhan, China. Lancet. 2020; 395:497-506. https://doi.org/10.1016/S0140-6736(20)30183-5 PMID:31986264

17. Chan JF, Yuan S, Kok KH, To KK, Chu H, Yang J, Xing F, Liu J, Yip CC, Poon RW, Tsoi HW, Lo SK, Chan KH, et al. A familial cluster of pneumonia associated with the 2019 novel coronavirus indicating person-to-person transmission: a study of a family cluster. Lancet. 2020; 395:514-23.

https://doi.org/10.1016/S0140-6736(20)30154-9 PMID:31986261

18. Choi KW, Chau TN, Tsang O, Tso E, Chiu MC, Tong WL, Lee PO, Ng TK, Ng WF, Lee KC, Lam W, Yu WC, Lai JY, Lai ST, and Princess Margaret Hospital SARS Study Group. Outcomes and prognostic factors in 267 patients with severe acute respiratory syndrome in Hong Kong. Ann Intern Med. 2003; 139:715-23. https://doi.org/10.7326/0003-4819-139-9-200311040$\underline{00005}$ PMID: 14597455

19. Hong KH, Choi JP, Hong SH, Lee J, Kwon JS, Kim SM, Park SY, Rhee JY, Kim BN, Choi HJ, Shin EC, Pai H, Park SH, Kim SH. Predictors of mortality in middle east respiratory syndrome (MERS). Thorax. 2018; 73:286-89.

https://doi.org/10.1136/thoraxinl-2016-209313 PMID:28724637

20. Zhou F, Yu T, Du R, Fan G, Liu Y, Liu Z, Xiang J, Wang Y, Song B, Gu X, Guan L, Wei Y, Li H, et al. Clinical course and risk factors for mortality of adult inpatients with COVID-19 in Wuhan, China: a retrospective cohort study. Lancet. 2020; 395:1054-62. https://doi.org/10.1016/S0140-6736(20)30566-3 PMID:32171076

21. MacLaren G, Fisher D, Brodie D. Preparing for the most critically ill patients with COVID-19: the potential role of extracorporeal membrane oxygenation. JAMA. 2020. [Epub ahead of print].

https://doi.org/10.1001/jama.2020.2342 PMID:32074258

22. Chen $G$, Wu D, Guo W, Cao Y, Huang D, Wang H, Wang $\mathrm{T}$, Zhang $\mathrm{X}$, Chen $\mathrm{H}, \mathrm{Yu} \mathrm{H}$, Zhang $\mathrm{X}$, Zhang $\mathrm{M}$, Wu S, et al. Clinical and immunological features of severe and moderate coronavirus disease 2019. J Clin Invest. 2020; 130:2620-29.

https://doi.org/10.1172/JCl137244 PMID:32217835
23. Li LQ, Huang $T$, Wang $Y Q$, Wang $Z P$, Liang $Y$, Huang $T B$,

Zhang HY, Sun WM, Wang YP. Response to char's comment: comment on li et al: COVID-19 patients' clinical characteristics, discharge rate, and fatality rate of meta-analysis. J Med Virol. 2020; 10:1002. https://doi.org/10.1002/jmv.25924 PMID:32320084

24. Guo L, Wei D, Zhang X, Wu Y, Li Q, Zhou M, Qu J. Clinical features predicting mortality risk in patients with viral pneumonia: the MuLBSTA score. Front Microbiol. 2019; 10:2752.

https://doi.org/10.3389/fmicb.2019.02752

PMID:31849894

25. Murillo-Zamora E, Medina-González A, Zamora-Pérez L, Vázquez-Yáñez A, Guzmán-Esquivel J, TrujilloHernández B. Performance of the PSI and CURB-65 scoring systems in predicting 30-day mortality in healthcare-associated pneumonia. Med Clin (Barc). 2018; 150:99-103.

https://doi.org/10.1016/j.medcli.2017.06.044 PMID:28778682

26. Brabrand M, Henriksen DP. CURB-65 score is equal to NEWS for identifying mortality risk of pneumonia patients: an observational study. Lung. 2018; 196:359-61.

https://doi.org/10.1007/s00408-018-0105-y PMID:29541854

27. Jingyuan L, Yao L, Pan X, Lin Pu, Haofeng Xiong, Chuansheng Li, Ming Zhang, Jianbo Tan, Yanli Xu, Rui Song, Meihua Song, Lin Wang, Wei Zhang, et al. Neutrophil-to-Lymphocyte Ratio Predicts Severe Illness Patients with 2019 Novel Coronavirus in the Early Stage. MedRxiv. 2020.

28. Xinhua News. Noah's Ark: the story of Fangcang shelter hospitals (in Chinese). Feb 19, 2020. [cited 2020 Feb 24]. http://www.xinhuanet.com/202002/19/c 1125598560.htm

29. Xinhua News. The number of people visiting fever clinic in Wuhan city can be as high as over 15000 per day (in Chinese). Jan 28, 2020. [cited 2020 Feb 9]. http://www.xinhuanet.com/202001/28/c 1125506630.htm

30. National health commission (NHC) of the PRC national administration of traditional Chinese medicine of the PRC. Guidance for Corona Virus Disease 2019: Prevention, Control, Diagnosis and Management. Beijing: People's medical publishing house; 2020. 


\section{SUPPLEMENTARY MATERIALS}

\section{Supplementary Figure}

A

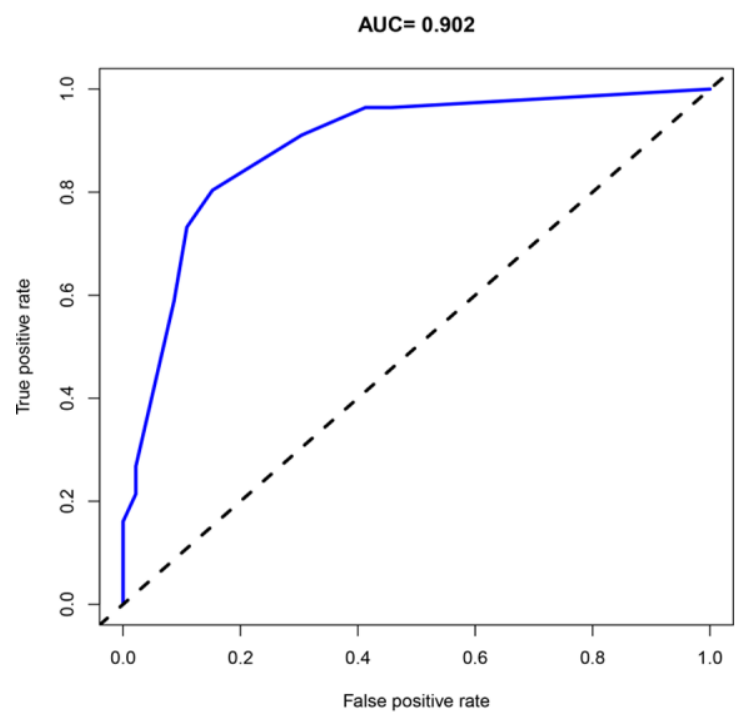

C

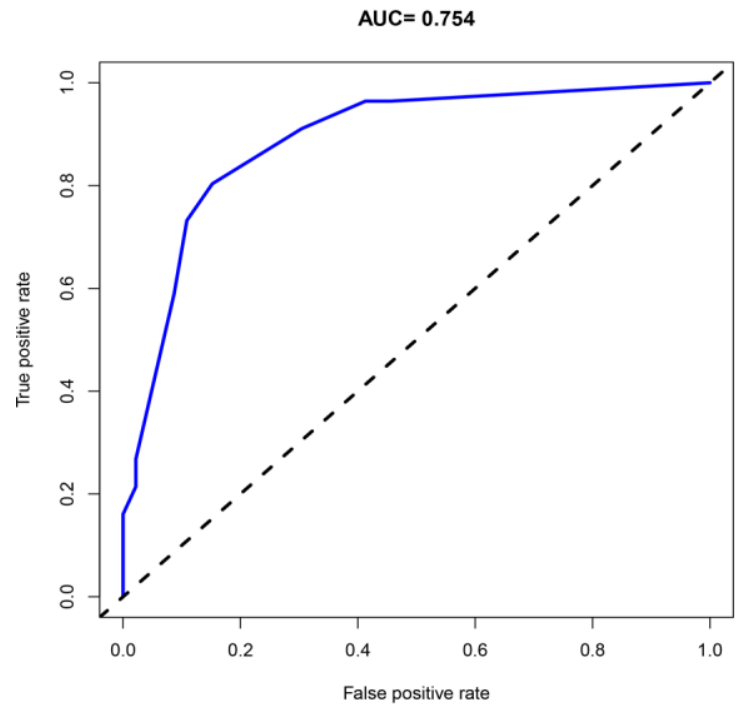

B

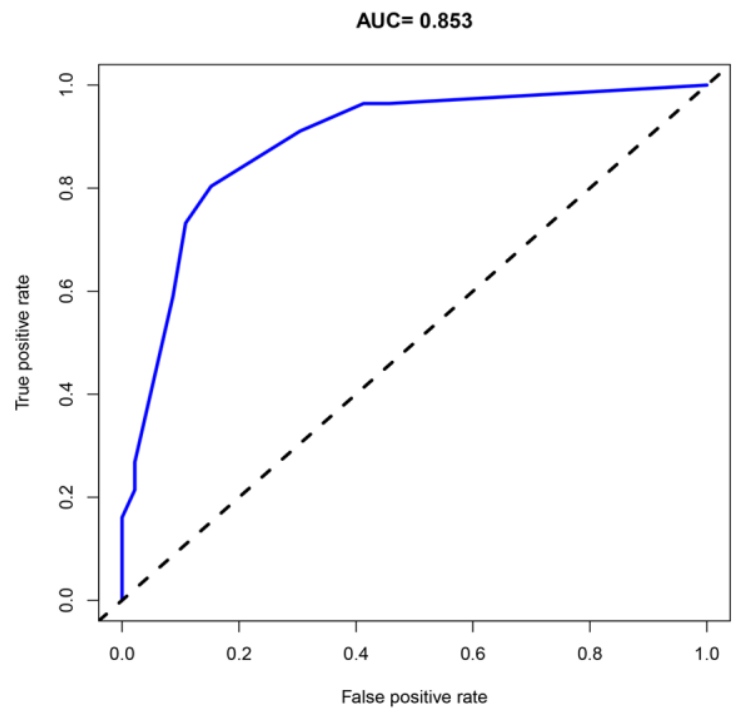

D

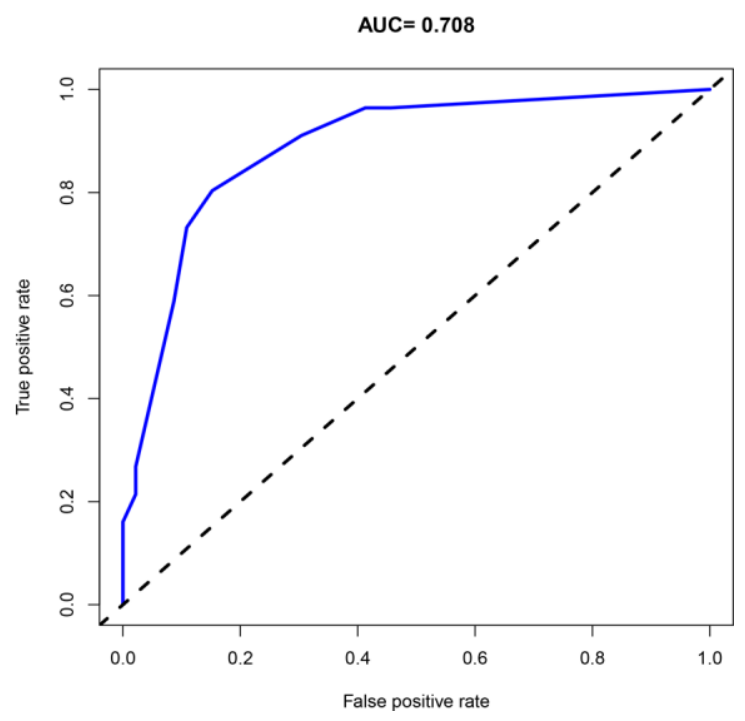

Supplementary Figure 1. Predictive value of four different models. Our prediction model (A); NLR (B), MULBSTA (C) and CURB-65 (D). 